\title{
Recurrent abdominal pain in children attending pediatrics OPD
}

\author{
Bansal S. $^{1}$, Une L. ${ }^{2 *}$ \\ DOI: https://doi.org/10.17511/ijpr.2020.i03.01 \\ 1 Sharad Bansal, Associate Professor, Department of Paediatrics, JIIU's Indian Institute of Medical Science and Research, Jalna, \\ Maharashtra, India. \\ 2* Lalit Une, Professor and Head, Department of Paediatrics, JIIU's Indian Institute of Medical Science and Research, Jalna, Maharashtra, \\ India.
}

Background: Recurrent abdominal pain is one of the commonest gastrointestinal complaints in children, affecting approximately $10 \%$ of school-aged children and adolescents. There is no consensus with regards to etiology, investigation, and management of this common problem. This article addresses some of the issues related to epidemiology, etiology, management, and prognosis of recurrent abdominal pain. Material and Methods: This was a hospital-based study conducted on 120 children patients with RAP. Patients of the age group of 4 to 14 years attending the pediatric OPD of Indian Institute of Medical Science and Research and Noor Hospital, from January 2019 to November 2019 were included in the study. Children age less than 4 years and more than 13 years not meeting the criteria of RAP were excluded from the study. Children with organic causes of RAP have been treated according to the corresponding reason. Results: Out of 120 patients of RAP, sex distribution is unequal with male predominance $(64.1 \%)$. Although in this study, age group was in the following order by decreasing 7-10 years old (43.3\%), followed by $4-6$ years old $(36.3 \%)$ and 11-14 years old (20\%). Conclusions: Organic disorder is still the commoner causes of RAP in our part of the world. Most children with recurrent abdominal pain have functional gastrointestinal diseases and detailed history, examination and basic stool, urine and hematological investigations are sufficient to exclude organic pathology in them. The key step in the management of RAP is to first investigate for the organic cause based on the symptoms and then treat.

Keywords: Abdominal pain, Children, Functional gastrointestinal disorder

\section{Corresponding Author}

Lalit Une, Professor and Head, Department of Paediatrics, JIIU's Indian Institute of Medical Science and Research, Jalna, Maharashtra, India. Email: lalit_68@yahoo.com

\section{How to Cite this Article}

Bansal S, Une L. Recurrent abdominal pain in children attending pediatrics OPD. Pediatric Rev Int J Pediatr Res. 2020;7(3):114-121.

Available From

https://pediatrics.medresearch.in/index.php/ijpr/arti cle/view/586
To Browse

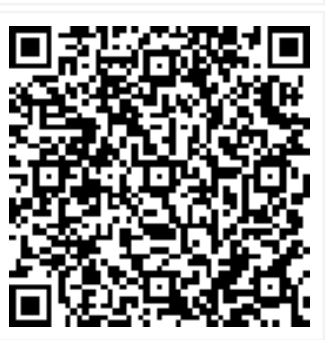

Accepted 2020-02-13 2020-02-07 Ethical Approval Yes
Review Round 3

Plagiarism X-checker $6 \%$
Note (c) 2020 by Sharad Bansal, Lalit Une and Published by Siddharth Health Research and Social Welfare Society. This is an Open
Access article licensed under a Creative Commons Attribution 4.0 International License https://creativecommons.org/licenses/by/4.0/ unported [CC BY 4.0]. 


\section{Introduction}

Recurrent abdominal pain (RAP) in children describes recurring abdominal pain without an organic cause. RAP in children is defined as abdominal pain which occurs at least four times a month over a period of two months or more, which is severe enough to limit a child's activities and which, after appropriate evaluation, cannot be attributed to another medical condition. It presents commonly in general practice and it causes a great deal of school absence and considerable anxiety.

RAP is believed to be a functional gut-brain interaction disorder (FGID) caused by altered feedback mechanisms between the gut and central pain pathways. There are several defined RAP patterns in children, of which pediatric irritable bowel syndrome (IBS) is the most common $[1,2]$. The original definition of RAP, published in 1958, including both organic and functional pain [3].

The prevalence of RAP affects $10-20 \%$ of schoolaged children worldwide [4]. 3-8\% of children with this pattern of pain have a causative organic pathology (and are excluded from the Rome definition of RAP). RAP occurs most commonly between ages 5 and 14 years. It is uncommon in children under 5 years of age. Boys are more commonly affected than Girls (relative prevalence 1.5). Prevalence in girls has led to suggestions that levels of sex hormones might play a role.

Ovarian hormones can modulate both visceral pain perception and the susceptibility to stress. There is an association between obesity and RAP [5]. There is an association between stress and RAP. Children with RAP are more likely to have experienced events such as deaths of family members, domestic violence, harsh punishment from parents, parental job loss and economic stress, hospitalization, and bullying. Children with a history of cow's milk protein hypersensitivity or abdominal surgery have an increased prevalence of FGIDs years later [6].

The pathophysiology involves dysregulation of visceral nerve pathways, leading to visceral hyperalgesia. Infective, inflammatory or psychological triggers may initiate this sensitization $[7,8]$. The onset of pediatric IBS frequently follows an episode of acute gastrointestinal inflammation (infectious or non-infectious) [9]. RAP is additionally affected by temperament and by family and school environments (the biopsychosocial model).
Less effective mechanisms of coping with stress may contribute to pain and to associated anxiety and depression [10] Poor diet, poor fluid intake and lack of exercise can contribute to RAP.

\section{Associated symptoms}

- Children with RAP are more likely to have a headache, joint pain, anorexia, vomiting, nausea, excessive gas, and altered bowel symptoms, although these symptoms may also occur in the presence of organic pathology. There is considerable overlap between recurrent headaches and recurrent abdominal pain [11].

- Children with RAP are more often diagnosed with anxiety or depressive disorders compared to unaffected children. Abdominal pain can cause depression/anxiety and, once developed, abdominal pain and depression/anxiety worsen each other.

- RAP leads to increased functional impairment in everyday life and school absence. $80 \%$ of affected children report school absence of at least one day in the previous term, compared to $45 \%$ in a control group. [12].

\section{Material and Methods}

Sample size: This was a hospital-based study conducted on 120 children patients with RAP.

Inclusion criteria: Patients of the age group of 4 to 14 years attending the pediatric OPD of Indian Institute of Medical Science and Research and Noor Hospital, from January 2019 to November 2019 were included in the study. A detailed history and clinical examinations, complete haemogram, urine for routine analysis as well as culture and stool examination were done in all cases. Other investigations like chest X-ray, ultrasonography performed where ever necessary.

Exclusion criteria: Children age less than 4 years and more than 13 years not meeting the criteria of RAP were excluded from the study. Children with organic causes of RAP have been treated according to the corresponding reason. Organic RAP was said to be present when;

- There was an organic cause documented

- There was both clinical and laboratory improvement with treatment and

- There was sustained clinical remission for at least three months after therapy. 
The patients who did not satisfy the above criteria were considered to have Non-organic RAP and were compared with an equal number of age and sexmatched controls, that comprised of children attending the Paediatric Outpatient Department

Statistical Analysis: All the data obtained were presented in percentages using Microsoft excel.

\section{Results}

Out of 120 patients of RAP, sex distribution is unequal with male predominance $(64.1 \%)$ and less female $(35.3 \%)$ (Table 1 ).

Table-1: Distribution of gender.

\begin{tabular}{|l|l|}
\hline \multicolumn{1}{|c|}{ Gender } & \multicolumn{1}{|c|}{$\mathrm{N}=\mathbf{1 2 0}$ (Percentage of cases) } \\
\hline Male & $77(64.1 \%)$ \\
\hline Female & $43(35.3 \%)$ \\
\hline
\end{tabular}

Table-2: Distribution of age group.

\begin{tabular}{|l|l|}
\hline \multicolumn{1}{|c|}{ Age group (in years) } & \multicolumn{1}{|c|}{$\mathrm{N}=\mathbf{1 2 0}$ (Percentage of cases) } \\
\hline $4-6$ & $44(36.3 \%)$ \\
\hline $7-10$ & $52(43.3 \%)$ \\
\hline $11-13$ & $24(20 \%)$ \\
\hline
\end{tabular}

Although in this study, age group was in the following order by decreasing 7-10 years old $(43.3 \%)$, followed by $4-6$ years old $(36.3 \%)$ and 11-14 years old (20\%) (Table 2 ).

Table-3: Characteristics: Organic RAP Versus Non-organic RAP.

\begin{tabular}{|c|c|c|}
\hline Parameters & $\begin{array}{l}\text { Organic RAP } n=14 \\
\qquad \%)\end{array}$ & $\begin{array}{c}\text { Non-organic RAP } n=106 \\
\qquad(\%)\end{array}$ \\
\hline \multicolumn{3}{|c|}{ The occurrence of abdominal pain } \\
\hline \multirow{3}{*}{$\begin{array}{l}\text { Once per week } \\
\text { Several times per } \\
\text { week } \\
\text { Everyday }\end{array}$} & $2(14.2 \%)$ & $23(21.6 \%)$ \\
\hline & $3(21.4 \%)$ & 36 (33.9\%) \\
\hline & $9(65.0 \%)$ & 47 (44.3\%) \\
\hline \multicolumn{3}{|c|}{ Duration of pain episodes } \\
\hline \multirow{4}{*}{$\begin{array}{l}\text { Less than } 1 \text { hour } \\
1-2 \text { hours } \\
\text { 3- } 4 \text { hours } \\
\text { Most of the day }\end{array}$} & $1(7.1 \%)$ & 37 (34.9\%) \\
\hline & $1(7.1 \%)$ & $29(27.3 \%)$ \\
\hline & $1(7.1 \%)$ & $12(11.3 \%)$ \\
\hline & $10(71 \%)$ & $28(26.4 \%)$ \\
\hline \multicolumn{3}{|l|}{ Severity of pain } \\
\hline \multirow{3}{*}{$\begin{array}{l}\text { Mild } \\
\text { Moderate } \\
\text { Severe }\end{array}$} & $1(7.1 \%)$ & $31(29.2 \%)$ \\
\hline & $4(28.5 \%)$ & $39(36.7 \%)$ \\
\hline & $8(60 \%)$ & $36(33.3 \%)$ \\
\hline \multicolumn{3}{|l|}{ Site of pain } \\
\hline \multirow{4}{*}{$\begin{array}{l}\text { Upper abdomen } \\
\text { Periumbilical } \\
\text { Lower abdomen } \\
\text { Other }\end{array}$} & $2(14.2 \%)$ & $9(8.4 \%)$ \\
\hline & $6(42.8 \%)$ & 49 (46.2\%) \\
\hline & $1(7.1 \%)$ & $26(24.5 \%)$ \\
\hline & $5(35.7 \%)$ & $22(20.7 \%)$ \\
\hline
\end{tabular}

\begin{tabular}{|c|c|c|}
\hline \multicolumn{3}{|l|}{ Duration of the disease } \\
\hline 2 months & $13(92.8 \%)$ & $5(4.7 \%)$ \\
\hline 3 months & 0 & $6(5.6 \%)$ \\
\hline 4-11 months & 0 & $4(3.7 \%)$ \\
\hline More than 12 months & $1(7.1 \%)$ & $91(85.0 \%)$ \\
\hline \multicolumn{3}{|l|}{ Bloating } \\
\hline Yes & $5(35.7 \%)$ & $34(32.0 \%)$ \\
\hline No & $9(64.2 \%)$ & 72 (67.9\%) \\
\hline \multicolumn{3}{|l|}{ Early satiety } \\
\hline Yes & $6(42.8 \%)$ & $35(33.0 \%)$ \\
\hline No & $8(57.1 \%)$ & $71(66.9 \%)$ \\
\hline \multicolumn{3}{|l|}{ Anorexia } \\
\hline Yes & $9(64.2 \%)$ & $72(67.9 \%)$ \\
\hline No & $5(35.7 \%)$ & $34(32.0 \%)$ \\
\hline \multicolumn{3}{|l|}{ Nausea } \\
\hline Yes & $4(28.5 \%)$ & $23(21.6 \%)$ \\
\hline No & $10(71.4 \%)$ & $83(78.3 \%)$ \\
\hline \multicolumn{3}{|l|}{ Vomiting } \\
\hline Yes & $3(21.4 \%)$ & $21(19.8 \%)$ \\
\hline No & $11(78.5 \%)$ & $85(80.1 \%)$ \\
\hline \multicolumn{3}{|l|}{ Constipation } \\
\hline Yes & $5(35.7 \%)$ & $75(70 \%)$ \\
\hline No & $9(64.2 \%)$ & $31(30 \%)$ \\
\hline \multicolumn{3}{|l|}{ Loose stools } \\
\hline Yes & $6(42.8 \%)$ & $22(20.7 \%)$ \\
\hline No & $8(57.1 \%)$ & $84(79.2 \%)$ \\
\hline \multicolumn{3}{|l|}{ Interference with sleep } \\
\hline Yes & $10(71.4 \%)$ & $43(40.5 \%)$ \\
\hline No & $4(28.5 \%)$ & $63(59.4 \%)$ \\
\hline \multicolumn{3}{|c|}{ Disturbance in daily activities } \\
\hline Yes & $11(78.5 \%)$ & $66(62.2 \%)$ \\
\hline No & $3(21.4 \%)$ & $40(37.7 \%)$ \\
\hline \multicolumn{3}{|l|}{ Headache } \\
\hline Yes & $4(28.5 \%)$ & $21(19.8 \%)$ \\
\hline No & $10(71.4 \%)$ & $85(80.1 \%)$ \\
\hline \multicolumn{3}{|l|}{ School absenteeism } \\
\hline Yes & $10(71.4 \%)$ & $43(40.5 \%)$ \\
\hline No & $4(28.5 \%)$ & $63(59.4 \%)$ \\
\hline \multicolumn{3}{|l|}{ Photophobia } \\
\hline Yes & $11(78.5 \%)$ & $84(79.2 \%)$ \\
\hline No & $3(21.4 \%)$ & $22(20.7 \%)$ \\
\hline \multicolumn{3}{|l|}{ Pallor } \\
\hline Yes & $4(28.5 \%)$ & $22(20.7 \%)$ \\
\hline No & $10(71.4 \%)$ & $84(79.2 \%)$ \\
\hline
\end{tabular}

In Table 3 In the current study, the Occurrence of abdominal pain every day in ORAP was 9 and 47 NORAP children, and once per week in organic ORAP was 2 and 23 NORAP children. The duration of pain episodes most of the day in ORAP was 10 and 28 NORAP children. 
Severe pain can see in 8 ORAP and 36 NORAP, and mild pain in 1 ORAP and 31 NORAP. Whereas, the site of pain especially in the periumbilical region in ORAP was 6 and 49 NORAP children, and lower abdomen pain in organic ORAP was 2 and 9 NORAP children. Moreover, 2 months duration of disease in ORAP was 13 and 5 NORAP children, and more than 12 months in ORAP was 1 and 91 NORAP children. In addition, the presence of bloating in ORAP was 5 and 34 NORAP children, and the absence of bloating in ORAP was 9 and 72 NORAP children. The presence of early satiety in ORAP was 6 and 35 NORAP children, and the absence of satiety in ORAP was 8 and 71 NORAP children.

Furthermore, in our results loss of appetite in ORAP was 9 and 72 NORAP children. The presence of nausea in ORAP was 4 and 23 NORAP children. The presence of vomiting in ORAP was 3 and 21 NORAP children. The deification of loose stools in ORAP was 6 and 22 NORAP children. Interference with sleep in ORAP was 10 and 43 NORAP children, and noninterference with sleep in ORAP was 4 and 63 NORAP children. Headache in ORAP was 4 and 21 NORAP children. School absenteeism in ORAP was 10 and 43 NORAP children. Photophobia was seen in ORAP was 11 and 84 NORAP children. Finally, pallor was seen in ORAP was 4 and 22 NORAP children.

\section{Discussion}

Pediatric RAP is a significant and prevalent problem, which can have a massive impact on a child's wellbeing, hitting school attendance, mood and their perception of their own health and fitness. If an over-prolonged search for the organic disease is pursued at the expense of thorough assessment, engagement, explanation, and review, the problem can become increasingly difficult for a parent, patient, and doctor [13].

However, with careful history and examination, clear explanation and follow-up and a commitment from parent and child to stop the condition limiting normal activities, good results are obtained for children without referral, drugs or extensive testing [14].

In the current study, teenagers with RAP had significantly lower quality of life (QoL) in all four domains; physical, emotional, social and school functioning. This lower QoL scores were significant in irritable bowel syndrome (IBS), abdominal migraine (AM) and functional abdominal pain (FAP).
Approximately $56 \%$ of affected children seek healthcare for their symptoms [15]. Factors independently associated with healthcare consultation were abdominal bloating and vomiting.

The current study did not find a relationship between QoL and age, gender, social class, maternal employment, family size, and birth order. The relationship between socio-demographic and family characteristics and HRQOL has not been evaluated in pediatric patients with RAP. However, contrary to our results, studies conducted in adult patients with functional gastrointestinal disorders have reported lower QoL in females compared to males. [16].

Recurrent abdominal pain is a common problem among children. Various studies have suggested that RAP is prevalent in 10 to $20 \%$ of the childadolescent population [17-19]. Mavromichalis et al in their study have demonstrated that organic causes constitute $93 \%$ of the study group [20]. Kumar et al found that $85 \%$ of the patient has affected due to organic causes of RAP [21]. The present study also revealed that $11.66 \%$ of the patient has been affected by RAP due to organic causes were the most common cause was a parasitic infestation. The current study has also found that $88.33 \%$ of the sampled patient population had non-organic causes of RAP. Five of them identified due to maladjustment either in school or in-home, four of them have got pica. Nothing abnormal is found in three cases. Previous studies revealed that among the non-organic RAP, maladjustment in family or school is the predominant cause and many patients of them had got a strong family history [22].

The mean duration of illness at the time of presentation was longer in the NORAP group possibly because patients with ORAP have their causes identified at some stage. Patients with functional disorders often have symptoms that closely mimic organic illnesses, hence it is not surprising that the characteristics of the pain were largely similar in both groups. The interference with sleep in the ORAP group is expected, as most functional disorders do not interfere with sleep patterns [23]. Nocturnal enuresis, a problem with a psychological basis, is understandably commoner among patients with NORAP [24].

The symptoms independently associated with healthcare consultation in the current study were abdominal bloating and vomiting. 
Similar to the current study, in the previous study conducted in children aged 5 to 15 years with recurrent abdominal pain, the only symptom associated with healthcare consultation was vomiting [25]. In contrast to this, other previous studies conducted in younger children have shown significant associations between health care consultation and age of onset, severity, frequency and duration of pain episodes, school absenteeism, sleep interruption and disruption of normal activity [26-28]. It is parents who take the children to see a doctor. Unlike younger children, teenagers are reluctant to discuss their bodily symptoms with their parents. Some of the parents may not be aware of these symptoms in their children. That may be a reason for the lack of association between healthcare consultation and some symptoms. However, a symptom like vomiting and bloating are visible to the parents and readily recognized. They are also alarming symptoms, especially in teenage girls in reproductive age. So those with bloating and vomiting are more likely to be taken to a doctor. In addition, due to variation in the perception of symptoms, the impact on the quality of life is more likely to influence healthcare consultation than the exact severity. In agreement with this, the current study found significantly lower scores for school functioning and physical functioning domains of QoL in healthcare consulters than in non-consulters.

The pathophysiology of RAP is thought to involve abnormalities in the enteric nervous system - a complex nervous system that envelops the entire gastrointestinal (GI) tract. Dysregulation of this brain-gut communication plays an important role in the pathogenesis of RAP [29]. Factors such as visceral hypersensitivity, altered intestinal motility, and visceral hyperalgesia could disrupt the brain-gut interaction and explain the cause of pain.

Changes in intraluminal pressure and mucosal inflammatory processes secondary to infections, allergies or primary inflammatory diseases may cause sensitization of afferent nerves associated with the onset of hyperalgesia [30]. At the molecular level, brain and gut peptides, mucosal immunology, inflammation and alterations in the bacterial flora of the gut probably provide the translational basis for GI symptom generation [31].

Many modalities of treatment such as dietary interventions, probiotics, pharmacological therapy, psychological support, and alternative medicine have been suggested, studied and screened.
However, since the pathophysiology of RAP is complex and multifactorial, there is no single form of therapy that can be recommended as first-line therapy. The potential power of the effect of placebo in treating children with RAP has been stressed [32]. A Cochrane review published the efficacy of three randomized controlled trials (RCTs) comparing Pizotifen versus placebo, peppermint oil capsules with placebo, and Famotidine with placebo. The authors concluded there was weak evidence of benefit on medications in children with RAP and there was little reason for their use beyond clinical trials [33].

A Cochrane review analyzed two RCTs and did not recommend the use of antidepressants in the management of abdominal pain-related FGID [34]. A recent RCT did not show a statistical difference of mebeverine over placebo either in the response rate or in the secondary outcome measures [35]. A Cochrane review of seven trials on the efficacy of dietary interventions concluded that there was a lack of evidence - be it fiber supplements, lactosefree diets or lactobacillus supplementation - in RAP [36]. The understanding of the biopsychosocial model of FGID opened the vistas for the use of psychosocial interventions, including parental education, family therapy, cognitive-behavioral techniques, relaxation, distraction, hypnotherapy, guided imagery and biofeedback [37].

Kaminski A, et al. compared four treatment protocols comprising different behavioral strategies, and concluded that the active treatment protocols assessed were better than the established reports [38]. Roohafza $H$, et al. reported that cognitivebehavioral family intervention significantly reduced the frequency of pain crises of children with nonorganic pain [39]. All these studies only indicate that there is no single therapy that has proven efficacy in managing children with FAP.

Few authors recommended modifications of lifestyle may be helpful. Dietary intervention is an important strategy adopted by many parents in managing RAP in their children. Increasing the amount of daily fiber intake has a marginal effect on improving abdominal pain. The use of probiotics has not been shown to be useful. Behavioral therapy for the management of children with RAP has been practiced in many centers in the world. Compared with standard therapies, cognitive behavioral therapy may be a more useful intervention for children with RAP $[41,42]$. 


\section{Limitation of the study}

01 . The current study has a smaller sample size, the large sample size is required for answering the question related to the ORAP and NORAP.

02. As the current study is a single-center study, large multicentre studies will help in the assessment of improved outcome which will be beneficial for our society.

03. The duration of study on a long term basis will help in more additional therapeutic benefits along with our primary outcome.

\section{Conclusions}

This study has assessed organic and non-organic RAP in Badnapur teenagers aged 4 to 13 years with abdominal pain predominant functional gastrointestinal diseases. The main symptoms associated with healthcare consultation were abdominal bloating and vomiting. The health-related quality of life was an important determinant of healthcare consultation, more than the severity of individual symptoms. Our results suggest that an organic cause such as giardiasis is the commonest cause of RAP. However, both organic and nonorganic factors need to be managed simultaneously for proper management of RAP.

\section{What does the study add to existing knowledge?}

Studies should target specific phenotypes of symptoms rather than RAP in general. Children should be categorized as per the Rome III criteria into separate disorders as there is a difference in etiology and response to therapy. Start a symptom diary. Explore with the family non-pharmaceutical pain management strategies such as muscle relaxation, art, movement, and imagery. Plan an early follow up appointment to review investigation results, diary entries, and pain management. The treatment goal is to ease pain and enable the child to function normally. Treatment should be individualized. Explanation and reassurance are all that is required in many cases. Referral to a child psychologist is recommended when anxiety or mood disorder is suspected and when symptoms are disabling and have not responded to first-line strategies. Note that children $<8$ years of age cognitively have difficulty understanding that feelings can cause physical symptoms.

\section{Author's Contributions}

Dr. Sharad Bansal: Concept and Manuscript preparation,

Dr. Lalit Une: Study design and data analysis.

\section{Reference}

01. Hardikar W, Feekery C, Smith A, Oberklaid F, Grimwood K. Helicobacter pylori and recurrent abdominal pain in children. J Pediatr Gastroenterol Nutr. 1996;22(2)148-152. [Crossref]

02. Bansal D, Patwari AK, Malhotra VL, Malhotra V, Anand VK. Helicobacter pylori infection in recurrent abdominal pain. Indian Pediatr. 1998;35;329-335.

Available at [Article] [Crossref]

03. Macarthur C, Saunders N, Feldman W, Ipp M, Winders-Lee $P$, Roberts $S$, et al. Helicobacter pylori and childhood recurrent abdominal painCommunity based case-control study. BMJ. 1999;319(7213)822-823.

[Crossref]

04. Apley J, Naish N. Recurrent abdominal pains- a field survey of 1000 school children. Arch Dis Child. 1958;33(168)165-170. doi: $10.1136 \% 2$ Fadc.33.168.165 [Crossref]

05. Boey CC, Goh KL. Recurrent abdominal pain and consulting behaviour among children in a rural community in Malaysia. Dig Liver Dis. 2001;33(2)140-144.

doi: $10.1016 / \mathrm{s} 1590-8658(01) 80069-4 \quad$ [Crossref]

06. Kokkonen J, Haapalahti M, Tikkanen S, Karttunene R, Savilahtl E. Gastrointestinal complaints and diagnosis in children- a population based study. Acta Pediatr. 2004;93(2)880-886.

doi: 10.1111/j.1651-2227.2004.tb02684.x [Crossref]

07. Pearl RH, Irish MS, Caty MG, Glick PL. The approach to common abdominal diagnosis in infants and children, Part II. Pediatr Clin North Am. 1998;45(6)1287-1326.

doi: $10.1016 / \mathrm{s} 0031-3955(05) 70092-4 \quad$ [Crossref] 
08. Thiessen PN. Recurrent abdominal pain. Pediatr Rev. 2002;23(2)39-46.

doi: $\quad 10.1542 /$ pir.23-2-39 [Crossref]

09. Liebman WM. Recurrent abdominal pain in children- lactose and sucrose intolerance, a prospective study. Pediatr. 1979;64(1)43-45.

[Crossref]

10. Wald A, Chandra R, Fisher SE, Gartner JC, Zitelli B. Lactose malabsorption in recurrent abdominal pain in childhood. J Pediatr. 1982;100(1)65-68. doi: $10.1016 /$ S0022-3476(82)80236-9 [Crossref]

11. Boey CC. Lactose deficiency among Malaysian children with recurrent abdominal pain. J Paediatr Child Health. 2001;37(2)157-160.

doi: $10.1046 / \mathrm{j} .1440-1754.2001 .00622 . x$ [Crossref]

12. Hyams JS, Burke G, Davis PM, Rzepski B, Andrulonis PA. Abdominal pain and irritable bowel syndrome in adolescents- a communitybased study. J Pediatr. 1996;129(2)220-226.

doi: $10.1016 / \mathrm{s} 0022-3476(96) 70246-9$ [Crossref]

13. Nurko S, Zimmerman LA. Evaluation and treatment of constipation in children and adolescents. Am Fam Physician. 2014;90(2)8290.

Available at: [Article] [Crossref]

14. Kline RM, Kline JJ, Di Palma J, Barbero GJ. Enteric-coated, pH-dependent peppermint oil capsules for the treatment of irritable bowel syndrome in children. J Pediatr. 2001;138(1)125-128.

doi: $10.1067 / \mathrm{mpd} .2001 .109606$ [Crossref]

15. Boey CC, Yap SB. An epidemiological survey of recurrent abdominal pain in a rural Malay school. J Paediatr Child Health. 1999;35(3)303305.

doi: $10.1046 / \mathrm{j} .1440-1754.1999 .00366 . x$ [Crossref]

16. Rasquin-Weber $A$, Hyman $P E$, Cucchiara $S$, Fleisher DR, Hyams JS, Milla PJ, et al. Childhood functional gastrointestinal disorders. Gut. 1999;45(2)1160-1168.

doi: 10.1136/gut.45.2008.ii60 [Crossref]
17. Boey CC, Yap S, Goh KL. The prevalence of recurrent abdominal pain in 11 - to 16 -year-old Malaysian schoolchildren. J Paediatr Child Health. 2000;36(2)114-116.

doi: $10.1046 / \mathrm{j} .1440-1754.2000 .00465 . x$ [Crossref]

18. Boey CC, Goh KL. Predictors of recurrent abdominal pain among 9 to 15 -year-old urban school-children in Malaysia. Acta Paediatr. 2001;90(3)353-355.

doi: 10.1111/j.1651-2227.2001.tb00318.x [Crossref]

19. Rasul CH, Khan MAD. Recurrent abdominal pain in school children in Bangladesh. J Ceylon Coll Phys. 2000;33;110-114.

[Crossref]

20. Mavromichalis I, Zaramboukas T, Richman PL, Slaving G. Recurrent abdominal pain of gastrointestinal origin. Eur J Pediatr. $1992 ; 151 ; 560-563$.

Available at [Article] [Crossref]

21. Kumar M, Yashha SK, Khanduri A, Prashad KN, Ayyagari A, Panday R. Endoscopic, histologic and microbiological evaluation of upper abdominal pain with special reference to $\mathrm{H}$ pylori infection. Indian Pediatr. 1996;33(11)905909.

[Crossref]

22. Walker LS, Lipani TA, Greene JW, Caines K, Stutts J, Polk DB, et al. Recurrent abdominal pain- symptom subtypes based on the Rome II criteria for pediatric functional gastrointestinal disorders. J Pediatr Gastroenterol Nutr. 2004;38(2)187-191.

doi: 10.1097/00005176-200402000-00016 [Crossref]

23. Huang RC, Plamer LJ, Forbes DA. Prevalence and pattern of childhood abdominal pain in an Australian general practice. J Paediatr Child Health. $2000 ; 36(4) 349-353$.

doi: $10.1046 / j .1440-1754.2000 .00513 . x$ [Crossref]

24. Devanarayana NM, de Silva DGH, de Silva HJ. Recurrent abdominal pain syndrome in a cohort of Sri Lankan children and adolescents. J Trop Pediatr. 2008;54(3)178-183.

doi: $10.1093 /$ tropej/fmm114 [Crossref] 
25. Boey CCM, Goh KL. Stressful life events and recurrent abdominal pain in children in a rural district in Malaysia. Eur J Gastroenterol Hepatol. 2001;13(4)401-404.

doi: 10.1097/00042737-200104000-00017 [Crossref]

26. Campo JV, Bridge J, Ehmann M, Altman S, Lucas $A$, Birmaher $B$, et al. Recurrent abdominal pain, anxiety, and depression in primary care. Pediatri. 2004;113(4)817-824.

doi: $10.1542 /$ peds.113.4.817 [Crossref]

27. Di Lorenzo C, Youssef NN, Sigurdsson L, Scharff L, Griffiths J, Wald A. Visceral hyperalgesia in children with functional abdominal pain. J Pediatr. 2001;139(6)838-843. doi: $10.1067 / \mathrm{mpd} .2001 .118883$ [Crossref]

28. Pace F, Zuin G, Di Gianomo S, Molteni P, Casini $V$, Fontana $M$, et al. Family history of irritable bowel syndrome is the major determinant of persistent abdominal complaints in young adults with a history of pediatric recurrent abdominal pain. World J Gastroenterol. 2006;12(24)38743877.

doi: $\quad 10.3748 \% 2 F w j g . v 12 . i 24.3874 \quad$ [Crossref]

29. Paul SP, Barnard P, Bigwood C, Candy DC. Challenges in management of irritable bowel syndrome in children. Indian Pediatr. 2013;50(12)1137-1143.

Available at [Article] [Crossref]

30. Giorgio V, D'Andrea V, Coccia P, Filoni S, Rendeli $C$, Fundarò C. Efficacy of rifaximin for SIBO treatment in IBS children. Pediatr Res. 2010;68(S1)144. doi: 10.1203/00006450-201011001-00280 [Crossref]

31. Gelfand AA. Migraine and childhood periodic syndromes in children and adolescents. Curr Opin Neurol. 2013;26(3)262-268.

doi: $10.1097 /$ wco.0b013e32836085c7 [Crossref]

32. Lagman-Bartolome AM, Lay C. Pediatric migraine variants. Curr Neurol Neurosci Rep. 2015;15(6)34.

doi: $\quad 10.1007 / \mathrm{s} 11910-015-0551-3 \quad$ [Crossref]
33. S Huertas-Ceballos A, Logan S, Bennett C, Macarthur C. Pharmacological interventions for recurrent abdominal pain (RAP) and irritable bowel syndrome (IBS) in childhood. Cochrane Database Syst Rev. 2008; 1;CD003017. doi: 10.1002/14651858.cd003017.pub2 [Crossref]

34. Kaminski A, Kamper A, Thaler K, Chapman A, Gartlehner G. Antidepressants for the treatment of abdominal pain related functional gastrointestinal disorders in children and adolescents. Cochrane Database Syst Rev. 2011;7;CD008013.

doi: 10.1002/14651858.CD008013.pub2 [Crossref]

35. Pourmoghaddas Z, Saneian H, Roohafza H, Gholamrezaei A. Mebeverine for pediatric functional abdominal pain- a randomized, placebo-controlled trial. Biomed Res Int. 2014;191026.

doi: $10.1155 / 2014 / 191026$ [Crossref]

36. Huertas-Ceballos AA, Logan S, Bennett C, Macarthur $C$. Dietary interventions for recurrent abdominal pain (RAP) and irritable bowel syndrome (IBS) in childhood. Cochrane database of systematic reviews. 2008(1)CD003019.

doi: 10.1002/14651858.cd003019.pub3 [Crossref]

37. Saps M, Di Lorenzo C. Pharmacotherapy for functional gastrointestinal disorders in children. J Pediatr Gastroenterol Nutr. 2009;48(2)S101S103.

doi: $10.1097 / \mathrm{mpg} .0 \mathrm{~b} 013 \mathrm{e} 3181 \mathrm{a} 15 \mathrm{f} 49$ [Crossref]

38. Kaminski A, Kamper A, Thaler K, Chapman A, Gartlehner $\mathrm{G}$. Antidepressants for the treatment of abdominal pain-related functional gastrointestinal disorders in children and adolescents. Cochrane Database Syst Rev. 2011;(7)CD008013.

doi: 10.1002/14651858.cd008013.pub2 [Crossref]

39. Roohafza H, Pourmoghaddas Z, Saneian H, Gholamrezaei A. Citalopram for pediatric functional abdominal pain- a randomized, placebo-controlled trial. Neurogastroenterol Motil. 2014;26(11)1642-1650.

doi: $10.1111 / \mathrm{nmo.12444}$ [Crossref] 
40. Chiou E, Nurko S. Functional abdominal pain and irritable bowel syndrome in children and adolescents. Therapy. 2011;8(3)315-331.

doi: 10.2217/thy.11.7 [Crossref]

41. Sadeghian M, Farahmand F, Fallahi GH, Abbasi A. Cyproheptadine for the treatment of functional abdominal pain in childhood. Minerva Pediatr. 2008;60(6)1367-1374.

[Crossref]
42. See MC, Birnbaum AH, Schechter $C B$, Goldenberg MM, Benkov KJ. Double-blind, placebo-controlled trial of famotidine in children with abdominal pain and dyspepsia. Dig Dis Sci. $2001 ; 46(5) 985-992$.

doi: $10.1023 / \mathrm{A}: 1010793408132$ [Crossref] 